http://doi.org/

DOI: doi.org/

\title{
Sistem Evaluasi Pasca Pelatihan di Rumah Sakit X Malang
}

\author{
Sri Suprapti \\ Program Studi Magister Manajemen Rumah Sakit \\ Fakultas Kedokteran Universitas Brawijaya Malang, Indonesia \\ prapti.martono15@gmail.com \\ Tuti Hariyanto ${ }^{2}$, Agung Putra Jaya ${ }^{3}$, Kurnia Widyaningrum ${ }^{4}$ \\ ${ }^{2,4}$ Program Studi Magister Manajemen Rumah Sakit \\ Fakultas Kedokteran Universitas Brawijaya Malang, Indonesia \\ tutipras@gmail.com, kurnia_widyaningrum@yahoo.com \\ ${ }^{3}$ Persada Hospital Malang \\ ucilagung@yahoo.com
}

\begin{abstract}
ABSTRAK
Efektifitas pelatihan dapat dinilai melalui evaluasi pasca pelatihan dengan menilai perilaku dan kompetensi hasil pelatihan. Rumah Sakit X dalam menilai efektifitas pelatihan didapatkan gap kecenderungan evaluator saat mengevaluasi alumni peserta latih memberikan nilai yang sama. Tingkat kesamaan dalam pemberian nilai kepada alumni peserta latih sebesar $85,53 \%$. Hal tersebut berdampak bias terhadap hasil evaluasi efektifitas pelatihan. Penelitian ini bertujuan untuk mengetahui dan menganalisis faktor penyebab utama, serta mencari alternatif solusi terhadap gap yang terjadi. Metode penelitian secara deskriptif dengan melakukan observasi, wawancara dan telaah dokumen, terhadap proses pelaksanaan dan hasil evaluasi efektifitas pelatihan. Ditindaklanjuti dengan melakukan focus group discussion untuk mengidentifikasi masalah. Beberapa masalah yang didapat diprioritaskan menggunakan metode USG (urgency seriouseness and growth). Hasil prioritas masalah dicari penyebab akar masalahnya menggunakan diagram fishbone. Penyebab utamanya adalah
\end{abstract}


http://doi.org/

belum adanya sistem dalam melakukan evaluasi pasca pelatihan. Penentuan Solusi menggunakan metode CARL (capability accesability readiness leverage) yaitu membuat pedoman evaluasi pasca pelatihan. Mengatur tentang: kriteria evaluator, tugas dan tanggung jawab evaluator, indikator evaluasi pasca pelatihan, instrumen evaluasi pasca pelatihan, pelaporan hasil dan rekomendasi evaluasi pasca pelatihan.

KataKunci: Evaluasi pasca pelatihan; pedoman evaluasi pasca pelatihan; pelatihan.

\title{
Post-Training Evaluation In X Hospital Malang
}

\begin{abstract}
The effectiveness of the training will be able to be assessed through post training evaluation by assessing the behavior and competency the outcomes of the training. In $X$ Hospital, in assessing the effectiveness of the training was found that the evaluator's tendency when evaluating the trainee alumni to give the same value to almost all participants who was being evaluated.The level of similarity in the value of trainees' alumni amounted to 85,53\%, it has a biased impact on the evaluation of the effectiveness of the training.This study aims to determine and analyze the main causal factors, as well as looking for the alternative solutions to the gap occurred. The research method is descriptive by doing observation, interviews and documents review of the implementation process and evaluation results of the effectiveness of the training. Followed up by focus group discussions to identify the problem. Some problems are found prioritized using USG (urgency seriouseness and growth) method. Result of priority problem search for based on the results of identification of the root cause of the problem by using the fishbone diagram. The main cause is there is not of the system in conducting post training evaluation yet. The solutions using the CARL (capability accesability readiness leverage) method, by making the recommendations of graduate training, in which compose about: criteria evaluator, task and responsibility of the evaluator, post-training evaluation indicators.
\end{abstract}

Keywords: Post-training evaluation; guidelines for post-training evaluation; training. 
http://doi.org/

\section{Pendahuluan}

Rumah sakit merupakan perusahaan pelayanan jasa, dimana produk yang dihasilkan sifatnya tidak berwujud (intangible) yang berasal dari pemberi pelayanan. Pemberi pelayanan tersebut adalah petugas rumah sakit yaitu sumber daya manusia (SDM), sehingga SDM merupakan unsur penting dalam produksi maupun penyampaian jasa. Sesuai dengan misi RS X, yaitu mewujudkan pelayanan prima kepada masyarakat melalui pelayanan kesehatan berstandar internasional, meningkatkan daya saing rumah sakit melalui pelayanan unggulan, dan meningkatkan profesionalisme sumber daya manusia. Misi tersebut dapat diwujudkan apabila SDM yang bertugas mampu meningkatkan mutu pelayanan. Sehingga diperlukan SDM yang berkualitas dan kompeten dibidangnya. Salah satu upaya untuk meningkatkan kualitas pelayanan dan kompetensi SDM dalam suatu organisasi dapat dengan cara menyelenggarakan pelatihan. Hasil pelatihan diharapkan dapat meningkatkan kompetensi, kinerja dan motivasi kerja karyawan. Pelatihan berbasis kompetensi merupakan suatu kegiatan pelatihan yang langsung dipraktikkan di lapangan sesuai dengan kebutuhan pekerjaan (Saraswati, 2015). Menurut Swasto B (2003), pelatihan berbasis kompetensi digunakan agar karyawan cepat dan mudah memahami pekerjaannya.

Pelatihan merupakan suatu upaya memfasilitasi peningkatan pengetahuan, keterampilan, dan perilaku terkait pekerjaan karyawan (Noe RA, 2003). Pendapat lainpun mengatakan bahwa pelatihan merupakan suatu usaha yang terencana untuk memfasilitasi pembelajaran tentang pekerjaan yang berkaitan dengan pengetahuan, keahlian, dan perilaku para pegawai (Fernandedez-Alles. M, Ramos-Rodriguez A, 2009).

RS X pada tahun 2017 memprogramkan 22 jenis pelatihan internal, terdiri dari 5 pelatihan mandatory akreditasi rumah sakit dan 17 pelatihan penunjang. Proses pelatihan yang dilakukan melalui tahapan perencanaan, pelaksanaan, monitoring dan evaluasi, serta pelaporan dan dokumentasi.

Pusdiklat Aparatur Badan PPSDM Kesehatan (2012) pada buku pedoman manajemen pelatihan di bidang kesehatan menyatakan bahwa, manajemen pelatihan sebagai siklus integral meliputi: analisa kebutuhan pelatihan, penetapan tujuan 
http://doi.org/

pelatihan, merancang program pelatihan, penyelenggaraan pelatihan, proses evaluasi pelatihan, dan pengendalian mutu. Namun penyelenggaraan pelatihan pada umumnya dalam melakukan evaluasi pelatihan hanya terfokus melakukan evaluasi sebelum dan saat pelatihan (proses) saja, sedangkan efektifitas pelatihan belum dilakukan.

Menurut WHO (1997) evaluasi pelatihan dapat difokuskan pada tahap-tahap tertentu dari manajemen dan perkembangan program pelatihan seperti evaluasi terhadap disain program pelatihan, evaluasi terhadap pelaksanaan program pelatihan yang disebut monitoring, atau evaluasi terhadap hasil program yang disebut evaluasi outcome (Pusdiklat Aparatur Badan PPSDM Kesehatan, 2015). Keberhasilan suatu pelatihan dapat diukur melalui evaluasi pelatihan.

Tahapan evaluasi pelatihan dilakukan sebelum (pre), saat pelatihan (proses), dan setelah (pasca) pelatihan. Evaluasi penilainya dapat menggunakan model Kirkpatrick's Four Levels Evaluation. Evaluasi dimulai dari tingkat satu sampai dengan empat secara berurutan. Evaluasi tersebut untuk mengukur: reaksi peserta latih terhadap program pelatihan, perubahan pengetahuan, keterampilan dan perilaku peserta latih ketika menerima kegiatan pembelajaran. Serta perubahan perilaku peserta latih akibat dari program pelatihan yang diikutinya, untuk mengukur hasil yang diperoleh peserta latih misalnya meningkatnya produktifitas kerja (Rukmi HS, Novirani D, Sahrul A, 2014).

Evaluasi reaksi dan evaluasi belajar dilakukan pada saat pelatihan/proses pembelajaran dilaksanakan. Sedangkan evaluasi perilaku dan evaluasi hasil dilakukan setelah peserta bekerja kembali di tempat kerjanya masing-masing (Rukmi HS, Novirani D, Sahrul A, 2014). Pelaksanaan evaluasi pasca pelatihan untuk menilai efektifitas pelatihan dalam teori model Kirkpatrick's four levels evaluation berada pada evaluasi perilaku (bahavior) dan evaluasi hasil (result).

RS X pada penyelenggaraan pelatihan telah melakukan evaluasi efektifitas pelatihan. Namun dalam pelaksanaannya masih didapatkan adanya gap, yaitu dalam menilai efektifitas pelatihan, terjadi kecenderungan evaluator saat mengevaluasi alumni peserta latih memberikan nilai yang sama kepada hampir seluruh peserta. Tingkat kesamaan dalam pemberian penilaian kepada alumni peserta latih sebesar 85,53\%. Hal tersebut berdampak bias terhadap hasil evaluasi efektifitas pelatihan. 
http://doi.org/

Tujuan dari penelitian ini untuk mengetahui dan menganalisis faktor penyebab utama, serta mencari alternatif solusi terhadap gap yang terjadi. Manfaat penelitian, dengan mengetahui gap dan faktor penyebabnya akan dapat diketahui alternatif solusi yang dapat dikelola oleh rumah sakit.

\section{Metode}

Penelitian dilakukan pada bulan September sampai dengan Oktober 2017, diawali dengan melakukan studi pendahuluan pada bulan Agustus 2017. Menggunakan metode deskriptif (Arikunto S, 2008), yang diawali dengan melakukan pengkajian data primer dan sekunder. Data primer diperoleh dengan melakukan observasi dan wawancara kepada Kepala Bidang SDM dan Hukum, Kepala Unit Diklat dan SDM dan penangung jawab penyelenggaraan diklat. Data sekunder diperoleh dengan menelaah dokumen hasil evaluasi efektifitas pelatihan.

Identifikasi masalah ditindaklanjuti dengan melakukan focus group discussion $(F G D)$, melibatkan enam orang Kepala Unit yang berperan juga sebagai tim evaluator dan dua orang penanggung jawab pelatihan. Penentuan prioritas masalah menggunakan metode urgency, seriousness, and growth (USG).

Masalah yang telah ditentukan diidentifikasi akar masalahnya dengan menggunakan fishbone. Akar masalah yang didapatkan, ditindaklanjuti dengan menentukan alternatif solusi menggunakan metode capability, accesability, readiness, leverage (CARL). Metode ini menggunakan kemampuan, kemudahan, kesiapan sumber daya yang ada dalam melaksanakan alternatif solusi, serta alternatif yang digunakan mempunyai daya ungkit dalam penyelesaian masalah.

\section{Hasil dan Pembahasan}

Data primer dan sekunder diperoleh dengan menelaah sumber-sumber dokumen meliputi: kebijakan rumah sakit, program kegiatan, standar prosedur operasional, pedoman, indikator mutu, dan laporan kegiatan. Hasil analisa data didapatkan adanya gap pada pelaksanaan penilaian efektifitas pelatihan. Evaluator memberikan penilaian kepada peserta pelatihan cenderung sama kepada hampir seluruh peserta yang 
http://doi.org/

dinilainya. Tingkat kesamaan dalam memberikan penilaian kepada alumni peserta latih sebesar $85,53 \%$. Form efektifitas pelatihan yang digunakan sebagai berikut di bawah ini:

Form efektifitas pelatihan yang digunakan saat ini di RS X Malang.

Metode evaluasi: Observasi (evaluasi lapangan)/ presentasi (internal training)/ kelulusan tes.

1. Kondisi sebelum pelatihan

\begin{tabular}{rl|l|l|l|l|l|l|l|l|l|}
1 & 2 & 3 & 4 & 5 & 6 & 7 & 8 & 9 & 10 \\
Tidak mampu
\end{tabular}

2. Kondisi sesudah pelatihan

\begin{tabular}{rl|l|l|l|l|l|l|l|l|l|}
1 & 2 & 3 & 4 & 5 & 6 & 7 & 8 & 9 & 10 \\
Tidak mampu
\end{tabular}

3. Pelatihan mendukung pekerjaan

\begin{tabular}{|l|l|l|l|l|l|l|l|l|l|}
1 & 2 & 3 & 4 & 5 & 6 & 7 & 8 & 9 & 10 \\
Tidak mendukung
\end{tabular}
Mendukung

Pelatihan dinyatakan efektif jika skor poin 2 lebih besar dari poin 1, dengan skor minimal 6.

Sumber: Form efektifitas pelatihan Persada Hospital.

Gambar 1. Form evaluasi pelatihan Persada Hospital saat ini.

Penilaian evaluasi efektifitas pelatihan dilakukan oleh atasan langsung yang berperan sebagai evaluator. Penilaian dilakukan 1 bulan setelah pelatihan. Form efektifitas pelatihan yang digunakan tidak memberikan indikator dan penjelasan pada penilaian. Hal tersebut diasumsikan menyebabkan terjadinya evaluator memberikan nilai yang sama kepada alumni peserta pelatihan.

Hasil evaluasi efektifitas pelatihan RS X bulan Januari sampai dengan Agustus 2017, tingkat kesamaan dalam pemberian penilaian sebagai berikut: (1) kondisi sebelum pelatihan $86,17 \%$ pada skor 5 dan 6 , (2) kondisi sesudah pelatihan $80,15 \%$ pada skor 7 dan 8 , (3) pelatihan mendukung pekerjaan $89,72 \%$ pada skor 7 dan 8.

Identifikasi masalah ditindak lanjuti dengan melakukan focus group discussion $(F G D)$ melibatkan Kepala Unit SDM dan Diklat, Kepala Unit Sekertariat, Kepala Unit Ruang Perawatan Maternal, Kepala Unit Radiologi, Kepala Unit Gizi, Kepala Unit Gawat Darurat, penanggung jawab pelatihan internal, dan pengnggung jawab pelatihan 
eksternal. Seluruh yang hadir berperan sebagai tim evaluator. Hasil $F G D$ didapatkan hasil sebagai berikut: (1) pelatihan yang dilaksanakan masih ada yang belum sesuai dengan kebutuhan unit kerja, (2) sistem evaluasi pasca pelatihan belum sesuai standar, (3) regulasi pelatihan yang belum tersosialisasi dengan baik. Ketiga masalah tersebut dilakukan penentuan prioritas masalah dengan menggunakan metode USG (urgency, seriousness, and growth), didapatkan hasil nilai tertinggi adalah sistem evaluasi pasca pelatihan belum sesuai standar.

Masalah yang telah ditentukan dilakukan identifikasi penyebabnya dengan menggunakan metode diagram fishbone. Penyebab masalah yang didapatkan meliputi: belum ada pedoman evaluasi pasca pelatihan (methode), belum ada indikator penilaian evaluasi pasca pelatihan, belum ada kriteria evaluator (material), evaluator belum mendapatkan pengetahuan dalam melakukan evaluasi pasca pelatihan (man), serta belum ada kurikulum pelatihan (machine).

Masalah yang didapatkan ditindaklanjuti dengan mencari alternatif solusi menggunakan metode capability accesability readiness leverage (CARL). Penentuan alternatif solusi dilakukan bersama-sama dengan Kepala Bagian SDM dan Hukum serta Kepala Unit Diklat dan SDM, didapatkan sebagai berikut: (1) membuat sistem evaluasi pasca pelatihan sesuai standar, (2) bekerjasama dengan pihak ketiga (konsultan atau organisasi profesi).

Pemilihan alternatif solusi berdasarkan hasil metode CARL didapatkan hasil: membuat sistem evaluasi pasca pelatihan sesuai standar mendapat skor 5.184 (I), bekerjasama dengan pihak ketiga (konsultan atau organisasi profesi) mendapat skor 2.352 (II). Solusi yang dipilih adalah membuat sistem evaluasi pasca pelatihan sesuai standar.

Kelebihan metode CARL adalah solusi yang relatif benyak, bisa ditentukan peringkat atas masing-masing masalah sehigga dapat diperoleh prioritas solusi yang akan dilakukan. Kekurangan metode CARL meliputi: penentuan skor sangat subyektif sehingga sulit distandarisasikan, penilaian atas masing-masing kriteria yang diskor perlu kesepakatan agar diperoleh hasil maksimal dalam penentuan peringkat (Azhari AD, 2015). 
http://doi.org/

Evaluasi pelatihan terhadap reaksi dan evaluasi belajar dilakukan pada saat pelatihan/ proses pembelajaran berjalan. Sedangkan evaluasi perilaku dan evaluasi hasil dilakukan setelah peserta bekerja kembali di tempat kerjanya masing-masing (Rukmini, 2014). Pelaksanaan evaluasi pasca pelatihan untuk menilai efektifitas pelatihan, dalam teori model Kirkpatrick's Four Levels Evaluation berada pada evaluasi perilaku (bahavior) dan evaluasi hasil (result) seperti pada gambar sebagai berikut di bawah ini:

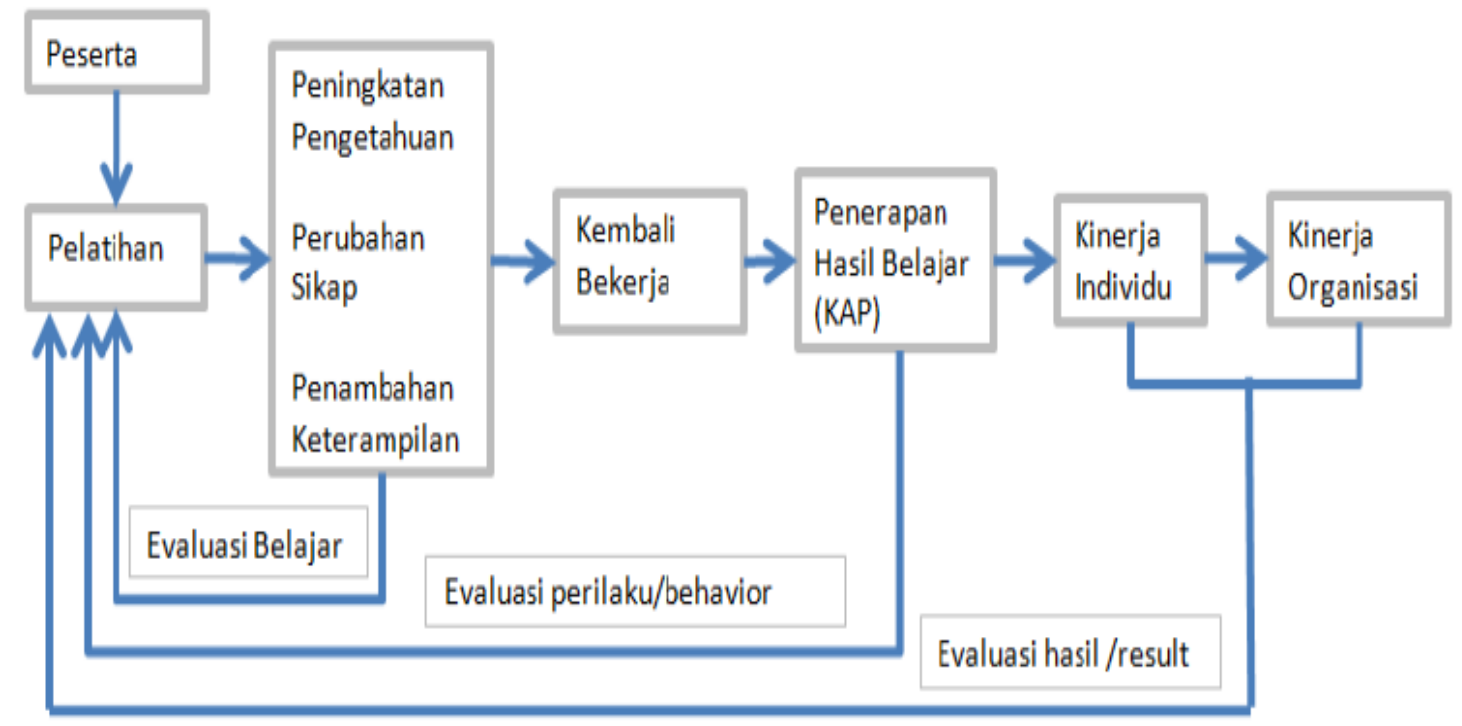

Sumber: Pedoman Evaluasi Pasca Pelatihan di Bidang Kesehatan, tahun 2015.

Gambar 2: Skema evaluasi pelatihan.

Evaluasi merupakan bagian dari siklus integral manajemen pelatihan (Pusdiklat Aparatur Badan PPSDM Kesehatan, 2012), yang dalam pelaksanaannya harus dilakukan dengan baik dan benar. Sehingga diperlukan adanya pedoman evaluasi pasca pelatihan. Hal ini didukung hasil penelitian Rukmi HS, dkk (2014), bahwa berdasarkan evaluasi behavior (level 3) dan results (level 4) didapatkan hasil sebagian besar peserta pelatihan cukup mampu mengaplikasikan materi pelatihan dengan baik di tempat kerja dan terjadi peningkatan presensi, yang berdampak pada penghematan perusahaan.

Tujuan evaluasi pasca pelatihan untuk mengetahui: (1) penyerapan pengetahuan, sikap, dan keterampilan yang terjadi pada alumni peserta latih yang diperoleh saat pelatihan, (2) komitmen para alumni peserta latih dalam mengaplikasikan pengetahuan, sikap dan keterampilan yang didapat saat pelatihan, (3) kemampuan alumni peserta latih 
dalam menjalankan tugas dan fungsinya ditempat kerja, (4) hambatan yang timbul dalam menjalankan tugas dan fungsinya terkait pelatihan yang telah didapat.

Tahapan yang dilakukan pada kegiatan evaluasi pasca pelatihan mulai dari perencanaan, pelaksanaan sampai dengan penyusunan laporan. Pada perencanaan ada beberapa kegiatan yang dilakukan, meliputi: (1) menentukan prioritas pelatihan yang akan dievaluasi, atau penentuan objek evaluasi, (2) membentuk tim evaluasi pasca pelatihan/ evaluator, (3) pengumpulan bahan - bahan evaluasi pasca pelatihan yang meliputi: kurikulum pelatihan dan dokumen laporan penyelenggaraan pelatihan, (4) tim membuat rencana evaluasi pelatihan dengan menyiapkan instrumen evaluasi sesuai dengan materi saat pelatihan.

Prioritas pelatihan yang akan dievaluasi merupakan pelatihan yang signifikan dalam meningkatkan kinerja SDM dan mempunyai daya ungkit terhadap peningkatan kinerja organisasi. Pelatihan yang dilakukan secara berkesinambungan, karena output evaluasi pasca pelatihan untuk memberikan masukkan agar pelatihan yang akan datang lebih baik sehingga dapat meningkatkan kompetensi. Tujuan pelatihan jelas dan dapat diukur.

Rekomendasi yang diberikan sebagai solusi pemecahan masalah sistem evaluasi pasca pelatihan belum sesuai standar adalah dengan membuat pedoman evaluasi pasca pelatihan. Sebagai acuan dalam mengukur keberhasilan pelatihan yang telah dilaksanakan dan dampaknya terhadap organisasi.

Penyusunan pedoman evaluasi pasca pelatihan bertujuan untuk memberikan panduan dalam langkah-langkah pelaksanaan dan penyusunan instrumen evaluasi efektifitas pelatihan, sesuai dengan jenis pelatihannya. Pedoman evaluasi pasca pelatihan bermanfaat untuk: (1) mengetahui kesesuaian kurikulum pelatihan dengan tuntutan kinerja individu, (2) mengetahui kelemahan- kelemahan dari program pelatihan yang digunakan untuk memperbaiki program pelatihan dimasa mendatang, (3) mengetahui apakah hasil pelatihan sesuai dengan tujuan yang telah ditetapkan, (4) dapat dijadikan sebagai bahan masukan untuk perumusan kebijakan pengembangan SDM, (5) mengetahui kelanjutan pelatihan yang telah dilakukan. 
http://doi.org/

Pedoman evaluasi pasca pelatihan didalamnya mengatur tentang: (1) indikator evaluasi pasca pelatihan, (2) kriteria evaluator, tugas dan tanggung jawab evaluator, (3) instrumen evaluasi pasca pelatihan, (4) pelaporan hasil dan rekomendasi evaluasi pasca pelatihan.

Indikator evaluasi pasca pelatihan meliputi: (1) indikator pelatihan, apakah pengetahuan yang diperoleh dari pelatihan yang diikuti dapat diimplementasikan untuk mendukung pekerjaan saat ini, (2) indikator sikap, apakah perubahan sikap yang terjadi pada saat mengikuti pelatihan dapat diubah menjadi perilaku kerja saat ini, (3) indikator skill, apakah keterampilan atau skill yang didapat pada saat mengikuti pelatihan dapat diiplementasikan guna meningkatkan kinerja individu dan kinerja organisasi.

Kriteria evaluator sebagai tim evaluasi pasca pelatihan (evaluator) sebaiknya dikukuhkan dengan Surat Keputusan (SK) Direktur Rumah Sakit, didalam SK dimuat tugas dan tanggung jawab tim serta jangka waktu pelaksanaan tugas. Persyaratan evaluator memiliki kompetensi manajerial, kompetensi teknis, dan kompetensi konseptual(Pusdiklat Aparatur Badan PPSDM Kesehatan, 2015).

Instrumen evaluasi pasca pelatihan digunakan untuk memberikan evaluasi pada: (1) dimensi kinerja meliputi: kualitas hasil kerja, inisiatif, kemampuan, (2) dimensi motivasi kerja meliputi: motivasi dan kondisi kerja, (3) dimensi kompetensi, sesuai dengan tujuan pelatihan. Untuk menilai keberhasilan yang telah dicapai oleh setiap peserta latih, setiap dimensi memiliki indikator capaian. 
http://doi.org/

Tabel 1. Instrumen Evaluasi Pasca Pelatihan

\begin{tabular}{|c|c|c|c|}
\hline Variabel & Indikator Hasil Kerja & $\begin{array}{cc}\begin{array}{c}\text { Kurang } \\
\text { baik }\end{array} & \begin{array}{c}\text { Cukup } \\
\text { baik }\end{array}\end{array}$ & $\begin{array}{c}\text { Sangat } \\
\text { baik }\end{array}$ \\
\hline \multicolumn{4}{|c|}{ Dimensi Kinerja } \\
\hline \multirow[t]{3}{*}{ Kualitas } & $\begin{array}{l}\text { Kepuasan terhadap hasil kerja alumni } \\
\text { pelatihan }\end{array}$ & & \\
\hline & $\begin{array}{l}\text { Prestasi terhapa hasil kerja alumni } \\
\text { pelatihan dalam melakukan kegiatan }\end{array}$ & & \\
\hline & $\begin{array}{l}\text { Pemahaman alumni terhadap hasil } \\
\text { pelatihan yang diikuti }\end{array}$ & & \\
\hline \multirow[t]{3}{*}{ Inisiatif } & $\begin{array}{l}\text { Kemampuan alumni pelatihan untuk } \\
\text { berpikir positif saat melakukan tugas }\end{array}$ & & \\
\hline & $\begin{array}{l}\text { Kemampuan alumni pelatihan untuk } \\
\text { menggunakan tindakan alternatif }\end{array}$ & & \\
\hline & $\begin{array}{l}\text { Kemampuan alumni terhadap respon } \\
\text { waktu dalam melakukan tugasnya }\end{array}$ & & \\
\hline Kemampuan & $\begin{array}{l}\text { Kemampuan alumni dalam menerapkan } \\
\text { teori yang didapat saat pelatihan dengan } \\
\text { penugasan yang dilakukan saat ini }\end{array}$ & & \\
\hline Komunikasi & $\begin{array}{l}\text { Kemampuan komunikasi kerja alumni } \\
\text { pelatihan dalam tim kerja }\end{array}$ & & \\
\hline \multicolumn{4}{|c|}{ Dimensi Motivasi Kerja } \\
\hline \multirow[t]{2}{*}{ Motivasi } & $\begin{array}{l}\text { Kesempatan/ peluang alumni pelatihan } \\
\text { untuk menerapkan hasil pelatihan }\end{array}$ & & \\
\hline & $\begin{array}{l}\text { Pengakuan tim kerja terhadap } \\
\text { kemampuan alumni pelatihan untuk } \\
\text { menerapkan hasil pelatihan }\end{array}$ & & \\
\hline Kondisi kerja & $\begin{array}{l}\text { Kondisi kerja saat ini setelah alumni } \\
\text { pelatihan menerapkan hasil pelatihan }\end{array}$ & & \\
\hline \multicolumn{4}{|c|}{ Dimensi kompetensi pelatihan } \\
\hline Variabel & Indikator keberhasilan & Tidak dilakukan & Dilakukan \\
\hline $\begin{array}{l}\text { Tujuan } \\
\text { pembelajaran } \\
\text { umum }\end{array}$ & Tujuan pembelajaran khusus & & \\
\hline
\end{tabular}

Pelaporan hasil rekomendasi evaluasi pasca pelatihan. Seluruh hasil observasi, wawancara di lapangan dicatat, dianalisa, disajikan dalam bentuk laporan hasil dan rekomendasi. Laporan yang disusun meliputi: (1) pendahuluan, yang memuat penjelasan umum, maksud dan tujuan, serta ruang lingkup, (2) kegiatan yang dilaksanakan, faktor yang mempengaruhi, hasil pelaksanaan kegiatan, hambatan yang dihadapi, dan hal lain yang perlu dilaporkan, (3) kesimpulan dan saran, sebagai bahan masukan serta pertimbangan, (4) penutup, merupakan akhir laporan, memuat harapan/ permintaan/ ucapan terimakasih.

Kegiatan pelaksanaan evaluasi pasca pelatihan meliputi: (1) konsolidasi tim, memantapkan rencana kerja tim, (2) mempelajari dokumen-dokumen yang telah 
dikumpulkan saat perencanaan: instrumen evaluasi yang akan digunakan, (3) menentukan objek peserta pelatihan yang akan dievaluasi. Evaluator turun ke lapangan untuk mengimplementasikan desain evaluasi yang telah dibuat. Pada tahap ini merupakan proses yang esensial dari kegiatan evaluasi program pelatihan, dikarenakan evaluator akan melakukan penilaian secara langsung, baik melalui metode observasi maupun wawancara kepada alumni peserta latih, atasan ataupun rekan kerja alumni.

Implikasi diketahuinya faktor penyebab dari gap yang terjadi pada evaluasi efektifitas pelatihan, maka rumah sakit dapat segera mencari solusinya. Solusi yang ditetapkan sesuai dengan masalah yang terjadi dan mampu dilaksanakan secara mandiri oleh rumah sakit. Sehingga dapat diketahui apakah pelatihan yang telah dilaksanakan dapat memberi dampak peningkatan pada kinerja individu dan organisasi.

Keterbatasan dalam penelitian ini adalah pada saat melakukan $F G D$ dari 16 evaluator, hanya 7 evaluator yang hadir $(43,75 \%)$. Dikarenakan evaluator adalah kepala unit yang memiliki tugas dan tanggung jawab kegiatan operasional pelayanan rumah sakit. Sehingga dalam menentukan kegiatan, akan lebih memprioritaskan tugas utama.

\section{Kesimpulan Dan Saran}

Faktor penyebab evaluator cenderung memberikan nilai yang sama kepada hampir seluruh alumni peserta latih dikarenakan belum adanya sistem evaluasi pasca pelatihan. Solusi yang direkomendasikan adalah dengan membuat pedoman evaluasi pasca pelatihan yang mengatur tentang: indikator evaluasi pasca pelatihan, kriteria evaluator, adanya instrumen evaluasi pasca pelatihan, serta pelaporan yang berisi hasil penilaian dan rekomendasi evaluasi pasca pelatihan. Hasil evaluasi pasca pelatihan akan berguna dalam menentukan kebijakan pimpinan dan mengambil keputusan-keputusan untuk mengatur strategi, menentukan program pelatihan yang bertujuan untuk perbaikan kinerja organisasi. 
http://doi.org/

\section{Daftar Pustaka}

Arikunto S. 2008. Prosedur Penelitian Suatu Pendekatan Praktek, Jakarta: Rineka Cipta. Fernandez-Alles. M dan Ramos-Rodriguez A (2009), Intellectual structure of human resources management research: A bibliometric analysis of the journal Human Resource Management, 1985-2005,. Journal of the Association for Information Science and Tecnology. 60 (1):161-175.

Noe RA, Hollenbeck JR, Gerhart B, Wright PM. 2003. Gaining a competitive advantage. Irwin: Mc Graw-Hill.

Pusdiklat Apatur Badan PPSDM Kesehatan. 2012. Pedoman Manajemen Pelatihan di Bidang Kesehatan, Jakarta: Kemenkes RI, Pp 24-28.

Pusdiklat Aparatur Badan PPSDM Kesehatan. 2015. Pedoman Evaluasi Pasca Pelatihan di Bidang Kesehatan, Jakarta: Kemenkes RI.

Rukmi HS, Novirani D, Sahrul A. 2014. Evaluasi Training Dengan Menggunakan Model Kirkpatrick (Studi Kasus Training Foreman Development Program Di PT. Krakatau Industrial Estate Cilegon). 5th National Industrial Engineering Conference.

Saraswati AB. 2015. Pengaruh Pelatihan Terhadap Kompetensi Karyawan dan Kualitas Pelayanan (Studi Pada Eco Green Park, Batu). Jurnal Administrasi Bisnis. 14(1).

Simamora H. 2003. Manajemen Sumber Daya Manusia, STIE YPKN.

Swasto B. 2003. Pengembangan Sumber Daya Manusia: Pengaruhnya terhadap Kinerja dan Imbalan. Bayumedia. 